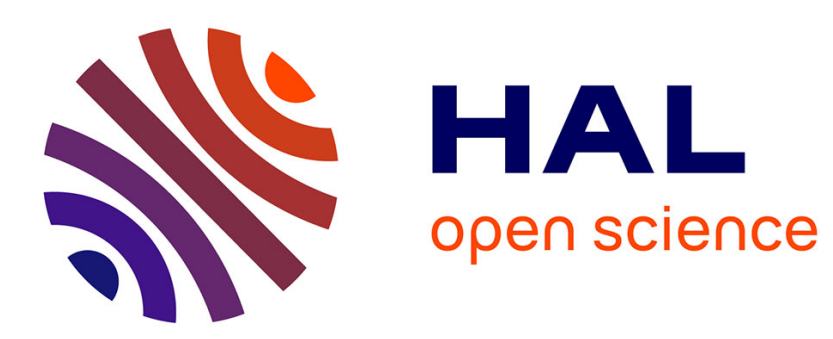

\title{
An experimental technique for measuring the temperature rise during impact testing
}

\author{
S. Craig, D. Gaskell, P. Rockett, C. Ruiz
}

\section{To cite this version:}

S. Craig, D. Gaskell, P. Rockett, C. Ruiz. An experimental technique for measuring the temperature rise during impact testing. Journal de Physique IV Proceedings, 1994, 04 (C8), pp.C8-41-C8-46. 10.1051/jp4:1994805 . jpa-00253335

\section{HAL Id: jpa-00253335 https://hal.science/jpa-00253335}

Submitted on 1 Jan 1994

HAL is a multi-disciplinary open access archive for the deposit and dissemination of scientific research documents, whether they are published or not. The documents may come from teaching and research institutions in France or abroad, or from public or private research centers.
L'archive ouverte pluridisciplinaire HAL, est destinée au dépôt et à la diffusion de documents scientifiques de niveau recherche, publiés ou non, émanant des établissements d'enseignement et de recherche français ou étrangers, des laboratoires publics ou privés. 


\title{
An experimental technique for measuring the temperature rise during impact testing
}

\author{
S.J. Craig, D.R. Gaskell, P. Rockett and C. Ruiz \\ Oxford University, Department of Engineering Science, Parks Road, Oxford OX1 3PJ, U.K.
}

\begin{abstract}
A fast response radiometer and its associated instrumentation for the measurement of the temperature reached during impact is described in this paper. It is based on a thermoelectrically cooled $\mathrm{HgCdTe}$ detector. The sensitivity and time response have been determined by means of static calibration tests, within the range +25 to $500^{\circ} \mathrm{C}$, and a dynamic calibration using an optical chopper at $1.35 \mathrm{kHz}$.

Some results of compression tests are provided.
\end{abstract}

\section{Introduction}

It has been shown [1] that about $90 \%$ of the energy of plastic deformation is dissipated as heat, while the remainder is retained within the material in the form of dislocation energy, energy due to the presence of defects and energy associated with their interaction. At low rates of strain, the rate of heating equals the rate of cooling and the process is isothermal. At much higher rates of strain however, the heat generation rate is much higher than the cooling rate and adiabatic heating causes a temperature increase. For example, in torsional tests on hot rolled steel conducted by Marchand and Duffy [2] at rates of $10^{+3} \mathrm{~s}^{-1}$, temperatures of up to $450^{\circ} \mathrm{C}$ were observed. The rise time may be only a few microseconds and depending upon the type of material, temperatures may exist for short time periods. Zehnder and Rosakis [3], who studied a dynamically propagating crack measured rise times of approximately $1.5 \mu$ s because propagation occurred at speeds ranging from $1000-2000 \mathrm{~s}^{-1}$. Fuller et al [4] also used infrared detectors and liquid crystals films to measure crack tip temperatures and the way in which the fracture surface energy changed with crack speed. In torsion tests on steel, Marchand and Duffy [2] recorded rise times of around $50 \mu s$ when testing at rates of around $10^{+3} \mathrm{~s}^{-1}$, while for compression tests on AL-2024, Mason et al [5] measured rise times of about $150 \mu \mathrm{s}$. The highest temperatures occur within shear bands which can be sometimes only a few microns wide and can appear anywhere within the gauge length of the test specimen, which poses the problem of knowing where to take the measurement. Any measuring device must therefore ideally have a response time of the order of $1 \mu \mathrm{s}$, have a spatial resolution of a few microns and must permit the measurement of temperature over a range dependent upon the material to be tested and the maximum strain rates involved.

The main advantages of high speed radiometry over other contacting methods such as thermocouples or heat sensitive films [6] are the ability to keep the instrumentation remote from the specimen and the fast response. 


\section{Infrared detector}

The infrared radiation was detected by means of a single element, HgCdTe device supplied by GECMarconi Infrared Limited. The photoconductive element had a size of $100 \times 100 \mu \mathrm{m}$ and a spectral bandwidth between $3-5.5 \mu \mathrm{m}$. Due to its high sensitivity, it was possible to detect radiation at wavelengths up to around $10 \mu \mathrm{m}$ corresponding to temperatures down to room temperature.

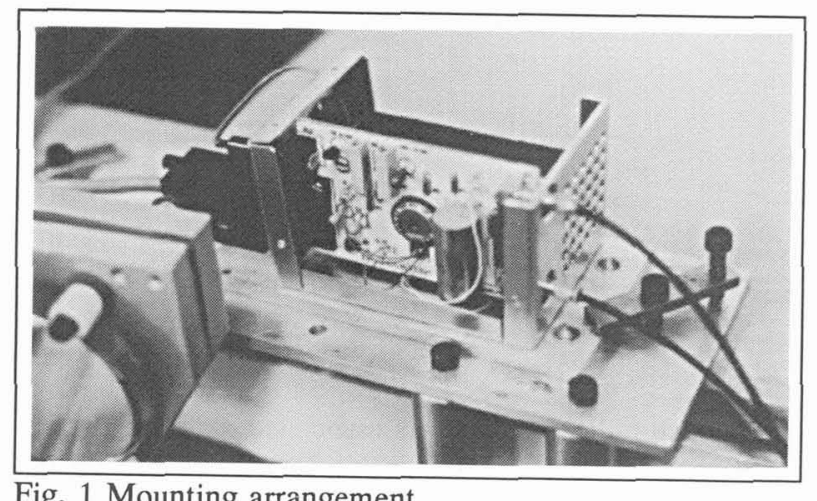

Fig. 1 Mounting arrangement

The detector and the associated electronics had a time response of $1.1 \mu \mathrm{s}$. The device was responsive to a.c. signals only and the cut-off frequency for the detector and amplifier together was approximately $145 \mathrm{KHz}$ corresponding to a minimal detectable rise time of $1.1 \mu \mathrm{s}$. The peak responsivity measured at $500 \mathrm{~Hz}$ was $18.1 \times 10^{3} \mathrm{~V} / \mathrm{W}$.

The element was kept at $-70^{\circ} \mathrm{C}$ by means of a thermoelectric cooler with an input power of $3 \mathrm{~W}$, which reduced the thermal noise and consequently increased the sensitivity by an order of magnitude. Detector and cooler were housed in a small capsule with a sapphire window which included a temperature sensing diode mounted on the element substrate. This enabled the element temperature to be monitored and if desired, controlled using the cooler. Stability and long life were expected from the encapsulation which was filled with a low thermal conduction gas. The element temperature was measured by forward biasing the diode with a constant current of $100 \mu \mathrm{A}$ and monitoring the resulting voltage. The output from the detector was amplified (see section 3.1) and then recorded using a Tektronix transient recorder. The encapsulation was mounted on an air cooled heat sink. The mounting arrangement is shown in the photograph of Fig. 1.

\section{Electronic circuits}

\subsection{Amplifier}

The two stage operational amplifier recommended by the manufacturers is shown in Fig. 2. A constant voltage bias of approximately $170 \mathrm{mV}$ was maintained across the detector which determined by the values of resistors R2 and R3. The current generated by the photoconductive element was converted to a voltage and then amplified.

Shown also is the constant current generator which supplied the temperature sensing diode with an $100 \mu \mathrm{A}$ bias current. It was essential that the circuit board track lengths were kept as short as possible to minimise electrical interference. It was found that on completion there was $25 \mathrm{mV}$ of noise on the output signal which was not ideal because the signal amplitude at low temperature was of the same order. It was decided therefore to improve the system by including a low pass filter.

Without the filter there was $25 \mathrm{mV}$ of noise on the output signal from the amplifier which meant that for temperature measurements below $55^{\circ} \mathrm{C}$, the signal-to-noise ratio exceeded one which was inadequate.

The noise frequency was predominantly in the order of $1 \mathrm{MHz}$. To improve the signal, the simple C-R low pass filter with a $1 \mathrm{k} \Omega$ resistor and a $8 \mathrm{nF}$ capacitor was placed in series between the amplifier output and the monitoring storage oscilloscope. The cut-off frequency, $\mathrm{f}_{\mathrm{c}}$ for the filter was $19.9 \mathrm{KHz}$, the 
result being a reduction in the noise amplitude from $20 \mathrm{mV}$ to $3 \mathrm{mV}$. The drawback with filtering the signal was that the response time of the system was reduced to around $50 \mu \mathrm{s}$, although this was still perfectly adequate for the purposes required.

\section{Optical arrangement}



Fig. 2 Amplifier circuit

The infrared radiation emitted from the surface of a specimen was focused onto the detector using the mirror arrangement shown in Fig. 3. The mirror coating consisted of a layer of gold $(0.1 \mu \mathrm{m}$ thick) on a chrome base ( $3 \mathrm{~nm}$ thick), providing $98 \%$ reflectivity across the $500 \mathrm{~nm}-10 \mu \mathrm{m}$ wavelength band. 


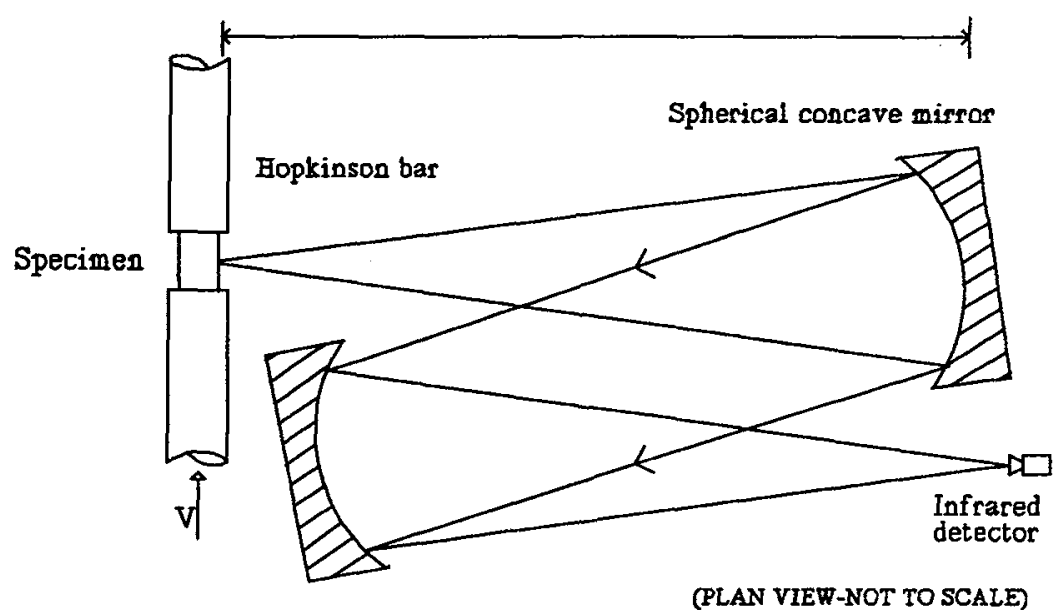

Fig. 3 Optical arrangement

\section{Calibration}

The black body radiation emitted from an electrically heated carbon block was focused onto the infrared detector.

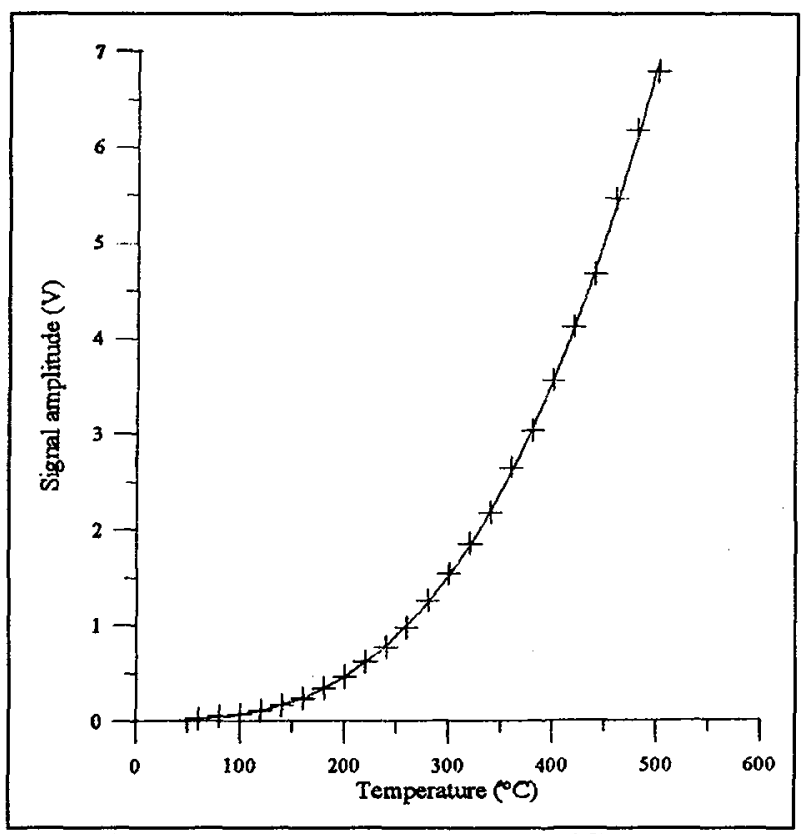

Fig. 4 Calibration curve between $0-500^{\circ} \mathrm{C}$.

The apparatus was encapsulated (except for a $15 \mathrm{~mm}$ diameter window enabling part of the radiation to escape) to form an oven that enabled the temperature to exceed $500^{\circ} \mathrm{C}$ and which was measured using a K-type thermocouple. The procedure for the calibration was to heat up the oven to $500{ }^{\circ} \mathrm{C}$ then allow it to cool down while simultaneously recording the signal amplitude from the detector and the actual temperature of the oven as measured by the thermocouple. The calibration was performed from $500{ }^{\circ} \mathrm{C}$ and the curve is shown in Fig. 4 which illustrates the non-linear characteristic. The detector could measure 
temperatures down to $20^{\circ} \mathrm{C}$.

\section{Time response}

The rise time for an infrared detector is determined usually by measuring the time in response to a high frequency input pulse, supplied commonly by either a laser diode or a $\mathrm{GaP}$ light emitting diode, both of which can be driven in the giga-hertz frequency range. The infrared detector was supplied as having a response of $1.1 \mu \mathrm{s}$ when used with the associated electronics. To check that this was indeed the case, the response of the whole system was re-estimated but by using a novel, more simple and cheaper method compared with those used normally.

The radiation emitted from the dummy specimen shown in Fig. 4 was focused onto the detector element and a $1 \mathrm{~mm}$ diameter aperture placed in the path close to the detector. Immediately beyond the aperture the radiation was then chopped at a known high frequency with a five slot disc driven by a small air turbine. For a disc with 5 slots, $\omega=2 \pi / 5 \mathrm{~T}$, where $\mathrm{T}$ is the time period of the output signal measured from the oscilloscope. Fig. 5 shows the position of the radiation beam in relation to the chopper and the corresponding output trace observed on the oscilloscope.



Fig. 5 Determination of the time response.

Knowledge of the radial distance between the axis of the chopper and the centre of the radiation beam, $r_{b}$, enabled the chopping velocity, $v_{b}$, to be determined. The actual time, $t_{\text {actual }}$ for either the leading or the trailing edge of the chopper blade to cross the beam could then be calculated. The apparent time, $t_{\text {apparent }}$ for this to occur was obtained by observation of the output trace on the oscilloscope.

Comparison of the two times provided information as to the response of the detector. For the test $\mathrm{t}_{\text {actual }}=12.3 \mu \mathrm{s}$, while $\mathrm{t}_{\text {apparent }}$ was measured to be approximately $14 \mu \mathrm{s}$, a $1.7 \mu \mathrm{s}$ delay, although $t_{\text {apparent }}$ could be measured only to within $+/-2 \mu$ s.

The detector was shown to operate therefore with a very fast time response somewhere in the region of a few microseconds and better than $5 \mu \mathrm{s}$, although because there were several possible sources of experimental error including the measurement of $r_{b}, d, T$ and inferring $t_{\text {apparent }}$, it was difficult to obtain a precise figure. The previous device used in the department by Noble [7], which was a commercially available infrared video camera, took $400 \mu$ s for a single line scan, so a considerable improvement was made.

\section{Application}

The radiometer has so far been used to take temperature measurements during compression tests on 
aluminium 2024 using the compressional split Hopkinson pressure bar. The cylindrical tests specimens were $9 \mathrm{~mm}$ in diameter and $8 \mathrm{~mm}$ long. One of the major problems associated with radiometry is knowing the surface emissivity and how it changes. For the present work the problem was overcome by covering all specimens with a thin layer of soot prior to testing so that the surface emissivity was known then to be about one, eliminating the need to know the emissivity of the particular material. Since the calibration curves were obtained for a black body the temperatures could be obtained directly.

In all cases the temperature started to rise shortly after the onset of plastic deformation and increased more rapidly some $30-50 \mu \mathrm{s}$ after the peak load and reached a maximum that was maintained for about $5-20 \mu$ s before dropping relatively slowly. For the six tests which were performed, maximum surface temperatures of between $100-140{ }^{\circ} \mathrm{C}$ were recorded some $85-150 \mu$ s after the peak load had been reached.

\section{Conclusion}

Upon completion the radiometer was found capable of measuring temperatures between room temperature and up to at least $500{ }^{\circ} \mathrm{C}$ with an unfiltered response time of better than $5 \mu \mathrm{s}$.

The temperatures measured during impact tests were found to vary from one test to another. The problem was knowing exactly what the detector was measuring because with only a single element there was no way of being certain. A knowledge of whether shear banding had occurred and if so wether a temperature localised to a band had been measured fully or partially, if at all, was not possible. To overcome this problem in the future a radiometer consisting of a 12 element linear array is currently being built which will enable the temperature distribution to be determined more accurately.

\section{References}

[1] Taylor, G.I. and Quinney, M.A., Proc. Royal Soc. A, 143, 307 - 326, (1934).

[2] Marchand, A. and Duffy, J., J. Mech. Phys. Solids, 36, $251-283$, (1988).

[3] Zehnder, A.T. and Rosakis, A.J., J. Mech. Phys. Solids, 39, 385 - 415, (1991).

[4] Fuller, K.N.G., Fox, P.G. and Field, J.E., Proc. Roy. Soc., A341, 537-577, (1975).

[5] Mason, J.J., Rosakis, A.J. and Ravichandran, G., Mech. Mater., 17, 135-146, (1994).

[6] Swallowe, G.M., Field, J.E. and Horn, L.A., J. Mat. Sci., 21, 4089-4096; (1986).

[7] Noble, J.P., D. Phil. Thesis, Univ. of Oxford, Dept. of Engng. Sci., (1993).

\section{Acknowledgments}

The infrared detector was supplied by GEC-Marconi Infrared Limited and the project was funded by the Ministry of Defence. 